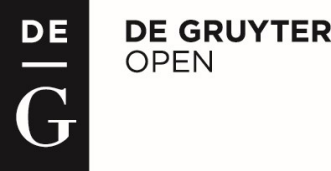

DOI 10.1515/sbe-2017-0031

\title{
DETERMINING MISSION STATEMENT EFFECTIVENESS FROM A FIT PERSPECTIVE
}

\author{
TOH Seong-Yuen \\ Sunway University, Malaysia \\ KOON Vui-Yee \\ Sunway University, Malaysia
}

\begin{abstract}
:
The purpose of this paper is to study the relationship between the organization's mission statement and its outcomes from a fit perspective in the alignment of the organization's structural and cultural elements. Based on an extension of Campbell's (1991) mission model by combination of ideas from two schools of thought in mission statement studies (structural and cultural), the authors introduce the concept of "fit" to show how it contributes towards a new mission statement model. The results show that both alignments are important to create a fit situation in order to positively impact organization outcomes. Based on Cohen (1988), the detected effect size of .322 is considered large. The managerial implication is that there should be more focus on managing organisational alignment to support a fit situation as this is instrumental to mission statement effectiveness. The originality of this study stems from the idea that while past studies develop model based on ideas from within the confine of a particular school of thought, this study is one of the first to combine ideas from both the structural and cultural schools of thought by extending Campbell's (1991) mission model using the fit perspective.
\end{abstract}

Key words: mission statement, sense of mission, alignment, fit, structure, culture, effectiveness, purpose

\section{Introduction}

Mission statement is the central document of the modern organisation which customarily captures the purpose of the organisation (Williams, 2008). Since Drucker $(1954,1974)$ and Levitt $(1960)$, the idea of defining the purpose of the organisation is widely practised (Rigby \& Bilodeau, 2013). For almost three decades since Pearce and David's (1987) pioneering study research into the effectiveness of the mission statement, studies have not been able to ascertain conclusive evidence of its 
contribution towards the firm's performance. The empirical findings have thus far been said to be mixed (Bart \& Baetz, 1998) and even contradictory (Desmidt, Prinzie, \& Decramer, 2011). Scholars expressed their surprise (Atrill, Omran, \& Pointon, 2005) and even embarrassment (Sidhu, 2003) at this lack of evidence. Desmidt et al. (2011) conclude that there is still a 'black box' linking mission statement and organisation outcomes.

Recent attempts to remedy the issue have suggested new approaches to the study of mission statement effectiveness. For instances, Williams et al. (2014) suggested the use of top management commitment as a moderator in a new model and David et al. (2014) recommended a reexamination of the mission statement from a customer perspective to align the firm's marketing strategy as a new direction in mission statement studies. These two approaches locate their solution within the strategic school of thought (Babnik, Breznik, Dermol, \& Trunk Širca, 2014; Campbell, Nash, Devine, \& Young, 1992). Scholars in the strategic school of thought focus on the strategic arrangement (for examples: policies, procedures, processes, systems and goals) of the organisation conditions to study mission statement effectiveness. These studies intend to show whether differences in the content of the mission statement will influence financial outcomes (Analoui \& Karami, 2002; Atrill et al., 2005; David, 1989; Klemm, Sanderson, \& Luffman, 1991; Pearce \& David, 1987; Rarick \& Vitton, 1995). This strategic school is differentiated from the cultural school of thought which view the mission statement as a text document that shapes the values, identity, meaning, and culture of the organisation (Campbell et al., 1992; Desmidt \& Heene, 2003; Ledoux, 2005; Swales \& Rogers, 1995). The primary emphasis of the cultural school of thought is not to determine mission statement effective per se, but rather to study how the mission statement shapes and provides meaning (Babnik et al., 2014). Our study extended Campbell's (1991) mission model by investigating the effect of the fit perspective of the organisation's strategic and cultural elements between organisation's mission statement and the performance outcomes.

\section{Definition of Mission Statement}

The definition of the mission statement is following Braun et al. (2012, p. 431); they proposed a more comprehensive definition of the mission statement to include three aspects, namely the future views (vision), purposes (mission), and values (philosophy) of the organisation. This definition of the mission statement is, in normal usage, synonymous with various related labels found in literature including "vision," "core ideology," "corporate philosophy," "credo," and "our story" (Williams, 2008). The mission statement has among its target audience all stakeholders who can include specifically employees, customers, shareholders, community, and the country and government (Abrahams, 1995; Amato \& Amato, 2002; Bart, 1999; Ireland \& Hitt, 1992; Pearce \& David, 1987; Williams, 2008). Kimball (1992) distinguishes between company mission statement and the written mission statement. This suggests that every company have a mission statement, but sometimes companies may not have the 
three aspects of the mission statement formally documented but rather assumed. In this study, we assumed that the written mission statement shares the similar characteristics with company mission statement. Therefore both are the same.

\section{Theoretical Development}

\section{Strategic Alignment}

The strategic element in Campbell's (1991) mission model consists of the purpose and strategy of the organisation. Campbell posits that the relationship between purpose and strategy will translate to standards of behaviours that will put ideas into actions to achieve desirable results. However, this does not show how individual behaviours which translate to performance can be aggregated to organisation-level performance. Literature has found this to be problematic (DeNisi \& Smith, 2014). To address this limitation, this study treated the broad concept of performance management system bundle as proposed by DeNisi and Smith (2014) as the strategic element instead.

Empirical research on performance management system is concerned to explain how to untangle the complexity of aggregating individual performances to the firm level. DeNisi and Smith (2014) reveals that the limitations of past studies with regards to the scalability of performance from individual to group level and to firm level. Recent attempt investigates the relationship between a bundle of human resource practices and organisation outcomes (Jiang, Lepak, Hu, \& Baer, 2012) have fruitfully shown that these practices had a direct positive relationship on financial performance. These practices consist of the entire human resource value chain that is labelled as performance management system bundle (PMSB) which includes recruitment, training, performance appraisal, compensation, incentives, benefits, promotion and career development (DeNisi \& Smith, 2014; Jiang et al., 2012). This broad concept of the PMSB provides the mechanism "linking changes in individual performance to changes in firm-level performance" (DeNisi \& Smith, 2014, p. 130). This PMSB construct is adopted as the organisation structure element in this study.

Alignment of organisation strategy with the mission statement is a prerequisite for performance (Bart, Bontis, \& Taggar, 2001; Bart \& Tabone, 1998; Ford et al., 2006; Koon, 2014). This study proposed that PMSB should be aligned with the organisational objectives. Martin's (2014) analysis of strategic planning process acknowledges the use of the mission statement as the necessary first step in deriving a "lofty and aspirational goal" (p. 80).

Past studies have shown that clarity in the mission statement (MC) is important for alignment of organisational arrangements (Bart, Archer, \& Ghasemzadeh, 1998; Bart, 1997; Sattari, Pitt, \& Caruana, 2011; Stone, 1996). The perception of mission statement clarity by key managers who are directly involved in managing business and people is important because managers play an active role in the strategic and cultural alignment of the organisation with the mission statement. When managers clearly perceive the contents of the mission statement they will be better able to influence 
others and improve the alignment of objectives, policies, and processes. For this reasons, the perspective of managers regarding mission statement clarity provides an accurate picture of the situation. Therefore, it is posited that clarity in expressing these contents of the mission statement as perceived by managers will have a positive effect on strategic alignment and organisation outcomes. Conversely, it is argued that a lack of clarity in expressing these components will hinder the effectiveness of managers in streamlining organisational systems, procedures, and policies to achieve a unity of direction and purpose. Bart et al. (2001, p.22) claimed that since it is widely reported that "for any strategy to be successful, there must be management systems and processes in place which are aligned with and which reinforce the strategy". Therefore it should be deduced that "the same should hold true for mission statements since they are traditionally viewed as one of the seminal components of the strategy." In fact in their research, Bart et al. (2001) have shown that alignment of organisation structure to the mission statement is positively linked to organisation outcomes. Therefore, using PMSB as strategic elements, we posited that:

\section{$\boldsymbol{H}_{1}: M C$ is positively related to $P M S B$.}

\section{Cultural Alignment}

Campbell's (1996) idea of sense of mission is associated with the concept of value congruence $(\mathrm{VC})$ between the employees and the organisation.

"Sense of mission is an emotional commitment... a match between the values of an organisation and those of an individual...The greater the link between the company policies and individual values, the greater the scope for the individual's sense of mission... We see the values match as the most important part of a sense of mission because it is through values that individuals feel emotional about their organisations." (Campbell, 1996, p. 1314).

This study conceives such values match in the concept of value congruence (VC) following Meglino, Ravlin \& Adkins's (1989) and O'Reilly, Chatman, \& Caldwell's (1991) studies of organisation culture as value congruence. Research has confirmed the link between employee values and employee perception, attitude and behaviour (Meglina et al., 1989). O'Reilly et al. (1991) further explain that people assume a social identity that provides connectedness and meaning. People gravitate towards others who are similar to themselves because they have similar values which reinforce this social identity. As such employees are attracted to organisations that have values in congruence with their own. People with shared values think similarly (Gardner, Reithel, Foley, Cogliser, \& Walumbwa, 2009). A high degree of value congruence implies a strong culture. "These similarities are presumed to foster comparable methods of classifying and interpreting environmental events, and a common system of communication ...thereby enhancing coordination, job satisfaction, and organizational commitment." (Meglino et al., 1989, p. 424).

It is widely acknowledged that the core values, ethical ideals, standards of 
behaviour of the organisation are encapsulated in the mission statement (Braun, Wesche, Frey, \& Weisweiler, 2012; Cady \& Wheeler, 2011; Campbell \& Yeung, 1991; Klemm et al., 1991; Pearce \& David, 1987; Williams, 2008). Posner, Kouzes, and Schmidt's (1985) study on shared values and their impact on managerial and organisational outcomes use the same concept of value congruence. In their study, they found that clarity in organisational values from managers is instrumental in improving individual and organisational performance. Their recommendation to improve clarify of organisational values includes implementing programmes for the management to clarify and reinforce their value statements or credos. Such value statements or credos are understood as a component of the formal mission statement (Braun et al., 2012). Therefore, we posited that a greater degree of mission clarity as perceived by managers of such desirable values and ethical standards is therefore expected to improve value congruence. Therefore,

\section{$\boldsymbol{H}_{2:} M C$ is positively related to $V C$.}

\section{A Fit Perspective}

A fit situation arises due to a positive reinforcing relationship between the strategic and cultural element. A higher degree of fit will result when both the strategic and cultural elements positively reinforce each other. This means, conversely, that a lack of fit is due to a lack of positive reinforcing relationship. If only one side provides a positive reinforcement and the other does not, then a lower degree of fit results. It is worth noting that Hartog and Verburg's understanding of "a fit perspective" as "an alignment" is different from this study. While they equate the two, in this study "alignment" is understood as "being in line with" or "in consonant with" while "fit" is understood as "a positive reinforcing relationship". When managers are not clear about the desired values and ethical standards espoused in the mission statement, they may face difficulties in aligning the culture and strategy. When these are not aligned, such a lack of fit may result. Venkatraman $(1989$, p.431) expresses the same idea of fit as "matching" by giving this illustration, "An example of this perspective is found in Chandler's (1962) classical thesis that a diversification strategy requires a multidivisional structure, whereas a geographical expansion strategy requires field units, and the absence of such a match between structure and strategy leads to administrative inefficiency or weaker performance".

Past studies show that human resource practices can positively influence organisation (DeNisi \& Smith (2014); Khatri, Wells, McKune, \& Brewer, 2006). For instance, researchers confirm that human resource practices like reward mechanism can promote certain behaviours, attitudes, and beliefs that become part of the desired organisation culture. DeNisi and Smith (2014) argue that such human resource practices impact the culture of the organisation. PMSB, which is the entire human resource value chain, is expected to impact the organisation culture, namely value congruence in this study. In the case study by Anson (2000) demonstrated the importance of human resource practices in shaping the organisation culture. For 
instance, in a high-tech firm that depends heavily on innovation and creative ideas, their employees need fresh perspective and space for experimentations and even failures. However, recruitment policies that only hire graduates with engineering degrees may hinders this in the long run (Anders, 2015; Segran, 2014).

On the other hand, organisation culture can also influence human resource practices as evidenced by Pascale and Athos's (1982) study which demonstrated that the organisation culture shapes employee attitudes and perceptions of strategic elements like the performance management system or reward system. For instance, Chow and Shan (2007) also confirmed that organisation culture has a strong influence on the type of human resource system adopted in Chinese technology firms. As the role of organisation culture impacting human resource systems is recognised (Carroll, Dye, \& Wagar, 2011) this study expected that organisation culture could impact PMSB.

PMSB and VC need to be aligned with the mission statement (Ford et al., 2006) as a prerequisite for performance (Mullane, 2002). The alignment of these two elements can give rise to a fit situation, which is a positive reinforcing relationship described earlier. Hartog and Verburg (2004) express similar understanding of such reciprocal influencing,

"HRM may contribute to both the emergence and maintenance of shared patterns of norms, values and informal rules within organisations. Thus, HRM practices and, more specifically, high-performance work practices may have an impact on organisational culture ... One can also argue the reverse. The dominant culture may influence the HRM policy and practices adopted by organisations. Likely, the influence runs both ways. Another type of proposition worth exploring is whether performance is better where HRM practices and culture align (a fit perspective). Research on all these perspectives is useful." (p. 58)

Therefore, we proposed that when PMSB and VC are aligned with a mission statement, a fit situation will arise.

$H_{3}: M C$ is positively related to FIT.

$\mathrm{H}_{4}:$ PMSB is positively related to FIT.

$H_{5}$ : VC is positively related to FIT.

We expected that when fit situation arises, it will impact organisation performance positively. A review of past studies showed that organisation outcomes (OC) are measured regarding reported financial data (Bart \& Baetz, 1998; Bart et al., 2001; Pearce \& David, 1987; Rarick \& Vitton, 1995). However, recently scholars criticise the appropriateness of using financial data to measure outcomes (Desmidt et al., 2011). They suggest measuring OC regarding non-financial measurements (Alavi \& Karami, 2009; Bart et al., 2001) which involves measuring the perception or satisfaction level of both behavioural and financial outcomes. In this study, we measured organisation performance using both financial and non-financial outcome from the perception of managers as to overcome the limitation of past studies. As such, we posited the below hypotheses:

$\boldsymbol{H}_{6}:$ FIT is positively related to OC. 
$H_{7}$ : VC is positively related to OC.

$H_{8}:$ PMSB is positively related to OC.

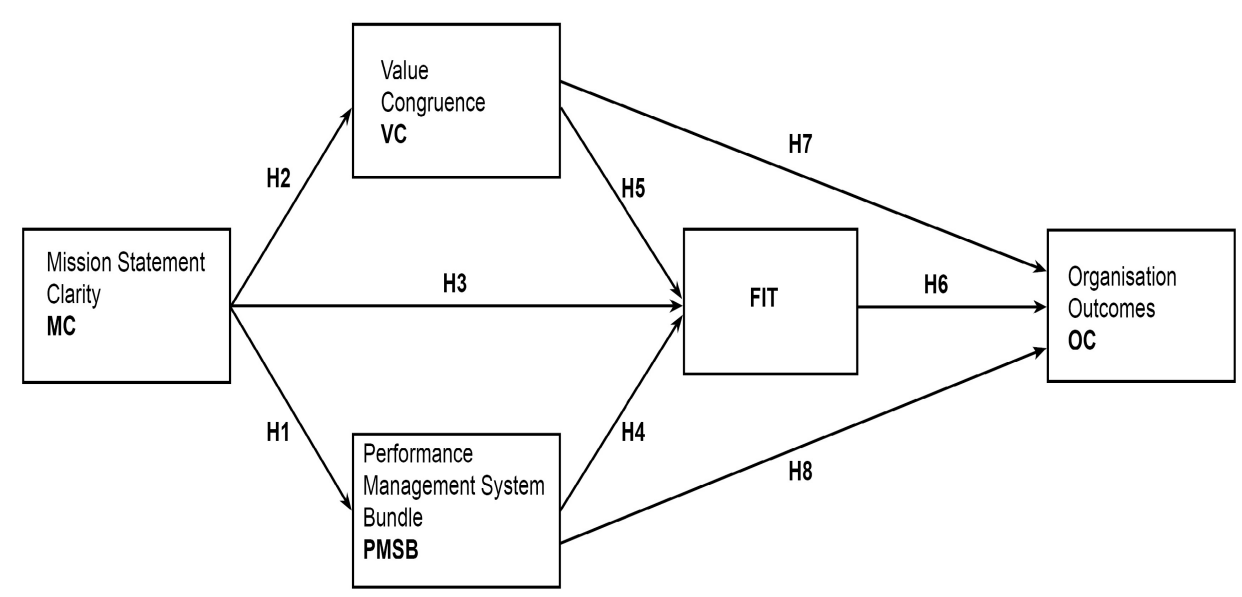

Figure 1

\section{Method}

\section{Procedure}

Purposive sampling technique was conducted using the survey questionnaire to collect data from managers who were studying MBA at a local university. Additionally, snowball sampling technique was utilised starting from direct contacts who are line managers and snowball to other acquaintances with similar career positions. A sample of 123 respondents participated in this cross-sectional study which is above the minimum sample size of 92 required for this study. The minimum sample size was based on a priori power analysis using the software package, Gpower (Faul, Erdfelder, Lang, \& Buchner, 2007) when a 5 predictor were used as a baseline. A medium effect size, $f^{2}=0.15$ (Cohen, 1988), the alpha level of $p<.05$ and statistical power of 0.80 as the minimum adequate level (Cohen, Cohen, West, \& Aiken, 2013) were used.

\section{Measurements}

MC was measured on core competencies (Sidhu, 2003), strategic boundaries (Desmidt et al., 2011), and purpose, values and vision (Braun et al., 2012) with a threepoint scale following Bart et al. (2001). Measurement of VC is based on Cable and DeRue (2002) who have studied the same dimensions of value fit. A further question measuring the dimension of higher value-fit over time as buy-in of employees increases based on a study by O'Reilly and Chatman (1986) was included. A sevenpoint scale was used. PMSB alignment was measured using an adapted version of the instrument used by Bart et al. (2001). PMBS alignment was measured regarding the 
extent to which the organisation's mission statement is "taken into account when determining" each practice in the whole human resource value chain. A five-point scale was used. To measure FIT, respondents were asked whether the culture encourages a generally positive attitude of employees toward the organisation's PMSB, improves employee acceptance, and commitment of the organisation's PMSB. Conversely, they were also asked whether PMSB promotes desirable employee behaviours, attitudes and beliefs in line with their organisation culture. A five-point scale was used. For organisation outcomes, non-financial outcomes were measured following Desmidt et al. (2011), Bart and Baetz (1998) and Campbell and Nash (1992). Moreover, to measure manager's perception of financial outcomes Bart, Bontis, and Taggar's (2001) method was adopted. A five-point scale was used.

\section{Results}

There is an almost even spread of male and female respondents (52:48) with $53 \%$ between 26 to 35 years old, the mean age of 34 . More than half $(59.3 \%)$ have between 1 to 10 staff reporting to them. They are educated (above $98 \%$ with a bachelor degree and above) and hold middle and top management positions (60.9\%). The majority of the respondents $(66 \%)$ work in their respective company between 2 to 10 years. About $48 \%$ of the respondents were not responsible for the profit and loss of the departments. However, this group of respondent have a mean tenure of about 7 years with an average of 5 subordinates reporting to them. As such, these respondents are appropriate to make a judgement about their company's mission statement.

\section{Data Analysis}

Partial Least Squares (PLS) techniques were used to analyse the model using the SmartPLS 3.0 software (Ringle, Wende, \& Becker, 2015). The procedure followed the Anderson and Gerbing's (1988) two-stage approach by testing the measurement model first and then testing the strategic model (Hair Jr, Hult, Ringle, \& Sarstedt, 2014; Henseler, Ringle, \& Sinkovics, 2009; Ramayah, Lee, \& In, 2011; Ramayah, Yeap, \& Ignatius, 2013).

\section{Common Method Variance}

Prior testing the measurement model, the Harman single factor test was used to detect common method bias (Bagozzi, Yi, \& Phillips, 1991; Podsakoff, MacKenzie, Lee, \& Podsakoff, 2003). The results from unrotated factor analysis revealed that the first factor accounted for $45.1 \%$ (less than $50 \%$ ). A correlation matrix was then used to detect $\mathrm{CMB}$ too, and results showed that the inter-correlation values were below 0.9 (off-diagonal values) and the indicators loading their respective constructs were greater than the cross-loadings. Finally, a more rigorous test for CMB following the suggestion by Podsakoff et al. (2003) was conducted. The test has been demonstrated by Liang, Saraf, Hu and Xue (2007) and explained by Siponen and Vance (2010). A comparison of the loadings shows that the average variance due to the constructs is $69.3 \%$ as 
compared to $3.7 \%$ for the method construct. Therefore, the results from these tests confirm that $\mathrm{CMB}$ is not problematic in this study.

\section{Measurement Model Evaluation}

First, the measurement model was assessed on convergent validity. Convergent validity was determined by examining the loadings, average variance extracted (AVE) and composite reliability of the measurement model (Gholami, Sulaiman, Ramayah, \& Molla, 2013). All recommended threshold values (Hair Jr et al., 2014) were exceeded (see Table 1) except for items F1, F2, F3 and F4. However, according to Hair et al. (2014, p. 103), when the outer loadings are between 0.4 and 0.7 , the items "should be considered for removal from the scale only when deleting the indicators lead to an increase in the composite reliability (or AVE) above the suggested threshold value." Since the CR and AVE values for OC are already above the threshold, F1, F2, F3 and F4 were not deleted. In conclusion, the measurement model has convergent validity.

Then, discriminant validity was first assessed using the Fornell and Larcker (1981) criterion. Table 2 shows all the values on the diagonals are greater than the rest of the measures indicating discriminant validity is present. Discriminant validity was further analysed using heterotrait-monotrait ratio of correlations (HTMT) (Henseler, Ringle, \& Sarstedt, 2015). HTMT is measured as a criterion and as a statistical test. As a criterion, HTMT value greater than 0.90 (Gold \& Arvind Malhotra, 2001) indicates a problem of a lack of discriminant validity. As a statistical test, HTMT is statistically tested for the null hypothesis $\left(\mathrm{H}_{0}: \mathrm{HTMT} \geq 1\right)$ against the alternative hypothesis $\left(\mathrm{H}_{1}\right.$ : $H T M T<1$ ). If the confidence interval includes 1 (i.e., $H_{0}$ is supported), this indicates a lack of discriminant validity. The results are shown in Table 3 indicate that the HTMT .90 criterions are met, and the HTMT Inference indicates no values of 1 in the constructs, thus indicating discriminant validity is confirmed. Therefore, the measurement model in this study has achieved discriminant validity.

Table 1: Measurement Model Analysis

\begin{tabular}{lllll}
\hline Construct & Item & Loadings & AVE $^{\mathrm{a}}$ & $\mathrm{CR}^{\mathrm{b}}$ \\
\hline MC & C1 & 0.728 & 0.547 & 0.857 \\
& C2 & 0.799 & & \\
& C3 & 0.734 & & \\
& C4 & 0.683 & & \\
& C5 & 0.745 & & \\
SOM & VF1 & 0.886 & 0.818 & 0.947 \\
& VF2 & 0.892 & & \\
& VF3 & 0.939 & & \\
& VF4 & 0.901 & & \\
PMSB & Align1 & 0.833 & 0.702 & 0.934 \\
& Align2 & 0.781 & & \\
& Align3 & 0.830 & &
\end{tabular}




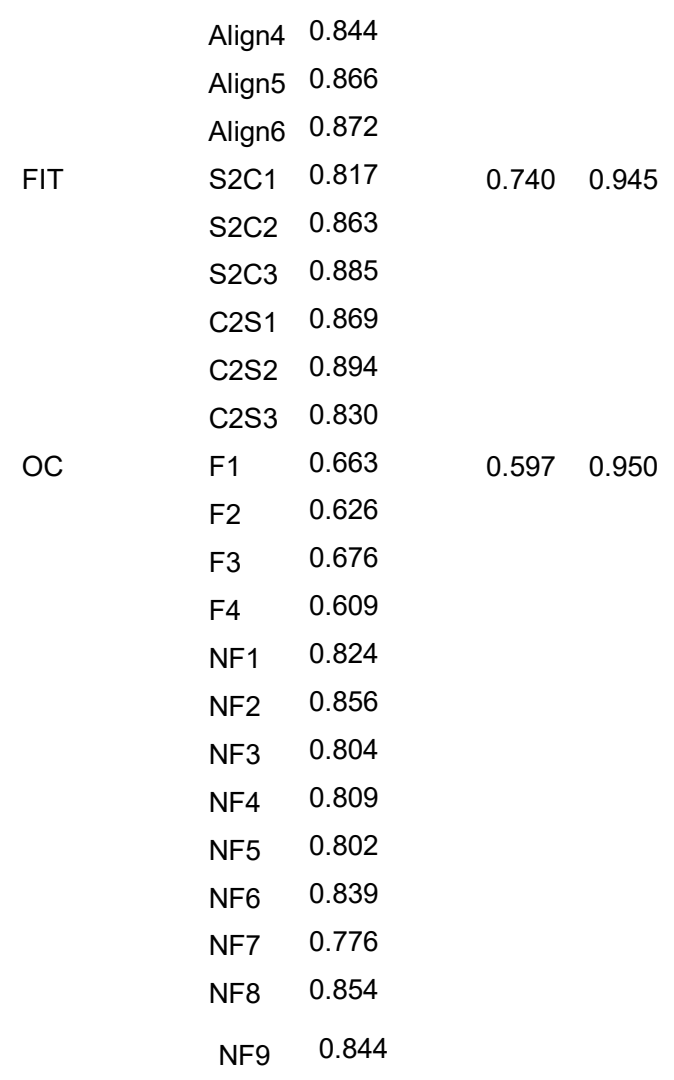

${ }^{a} \mathrm{AVE}=$ (summation of squared factor loadings)/(summation of squared factor loadings) (summation of error variances)

${ }^{b} \mathrm{CR}=$ (square of the summation of the factor loadings)/[(square of the summation of the factor loadings)+ (square of the summation of the error variances)]

Note. $\mathrm{MC}=$ Mission Clarity, $\mathrm{PMSB}=$ Performance Management System Bundle, $\mathrm{SOM}=$ Sense of Mission, $\mathrm{OC}=$ Organisation Outcomes, FIT = PMSB-SOM Fit

Table 2: Discriminant Validity

\begin{tabular}{llllll} 
& SOM & FIT & MC & OC & PMSB \\
\hline SOM & $\mathbf{0 . 9 0 5}$ & & & & \\
FIT & 0.646 & $\mathbf{0 . 8 6 0}$ & & & \\
MC & 0.488 & 0.465 & $\mathbf{0 . 7 3 9}$ & & \\
OC & 0.603 & 0.766 & 0.420 & $\mathbf{0 . 7 7 3}$ & \\
PMSB & 0.655 & 0.682 & 0.366 & 0.730 & $\mathbf{0 . 8 3 8}$
\end{tabular}

Note. Diagonals (bolded) represent the square root of the average variance extracted while the off-diagonals are correlations among constructs. Diagonal elements should be larger than off-diagonal elements in order to establish discriminant validity. $\mathrm{MC}=$ Mission Clarity, $\mathrm{PMSB}=$ Performance Management System Bundle, SOM = Sense of Mission, OC = Organisation Outcomes, FIT = PMSB-SOM Fit 
Table 3: Heterotrait-Monotrait (HTMT)

\begin{tabular}{lllll}
\hline & 1 & 2 & 3 & 4 \\
\hline MC & & & & \\
& 0.489 & & & \\
OC & $\mathrm{Cl}_{.90}(0.344,0.656)$ & & & \\
& 0.425 & 0.770 & & \\
PMSB & $\mathrm{Cl}_{.90}(0.264,0.605)$ & $\mathrm{Cl} .90(0.688,0.850)$ & & \\
& 0.566 & 0.632 & 0.707 & 0.692 \\
SOM & $\mathrm{Cl} .90(0.421,0.693)$ & $\mathrm{Cl}_{.90}(0.521,0.736)$ & $\mathrm{Cl} .90(0.601,0.803)$ & \\
& 0.533 & 0.796 & 0.733 & $\mathrm{Cl}_{.90}(0.600,0.779)$ \\
\hline
\end{tabular}

Note. $\mathrm{MC}=$ Mission clarity, $\mathrm{PMSB}=$ Performance management system bundle, SOM = Sense of mission, $\mathrm{OC}=$ Organisation Outcomes, FIT = PMSB-SOM Fit

\section{Strategic Model Evaluation}

Table 4 shows the results of the strategic model analysis. According to Hair et al. (2014), the strategic model is evaluated by referring to the $R^{2}$, beta and their respective $\mathrm{t}$-values. The $\mathrm{t}$-values are obtained by a bootstrapping procedure using 5,000 resampling. Predictive relevance $\left(\mathrm{Q}^{2}\right)$ and effect sizes $\left(\mathrm{f}^{2}\right)$ are also reported. The effect size $\left(\mathrm{f}^{2}\right)$ guideline is provided by Cohen (1988) who suggested that there is a small, medium or large effect when $\mathrm{f}^{2}$ values are $0.02,0.15$ and 0.35 respectively. According to Hair et al. (2014, p.186), " $R^{2}$ values of $0.75,0.50$, or 0.25 for endogenous constructs can be described as respectively substantial, moderate, and weak." Based on the results in Table $4, R^{2}$ values of FIT and OC (0.557 and 0.667 respectively) are moderate, and the $R^{2}$ values of the PMSB and VC constructs $(0.132$ and 0.238 respectively) are weak.

\section{Table 4: Structural Model Analysis}

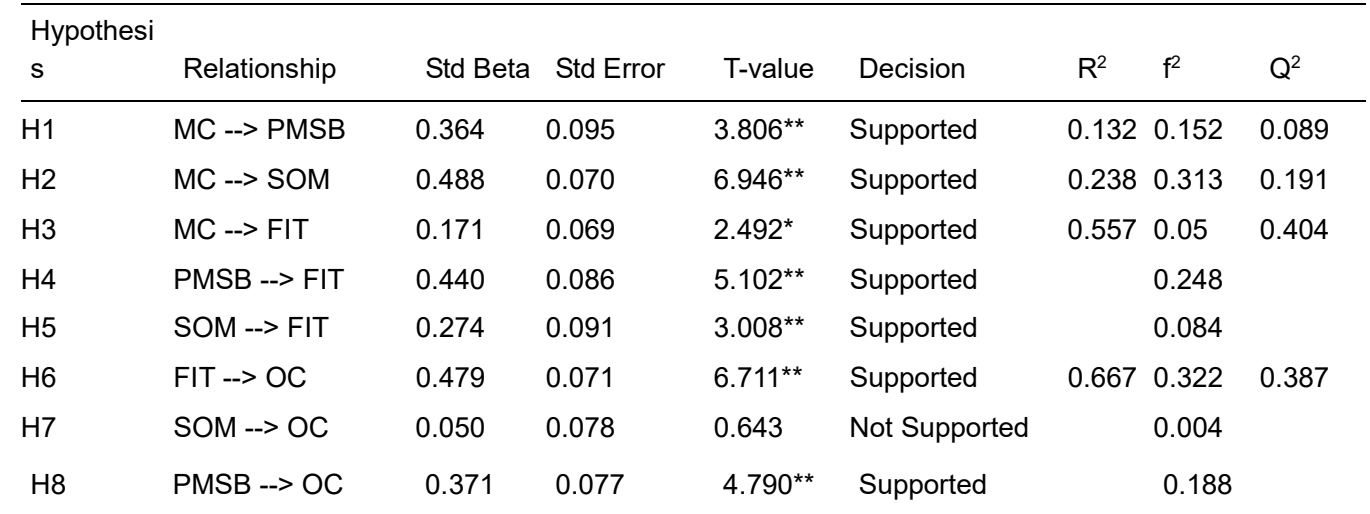

Note. MC = Mission Clarity, PMSB = Performance Management System Bundle, FIT = PMSB-SOM Fit, OC = Organisation outcomes

${ }^{*} \mathrm{P}<.05 .{ }^{*} \mathrm{P}<.01$ 
Hair et al. (2014) also suggested the $\mathrm{Q}^{2}$ values of more than 0 denote sufficient predictive relevance for the model where $Q^{2}$ values of $0.02,0.15$ and 0.35 indicate small, medium, and large predictive relevance respectively of an exogenous construct for certain endogenous construct. Based on the results, all exogenous constructs have sufficient predictive relevance, and since $Q^{2}$ of organisation outcomes is 0.387 , we conclude that the model has large predictive relevance.

The hypothesis $\left(\mathrm{H}_{1}\right)$ that mission clarity is positively related to PMSB alignment is supported by the results $(\beta=0.366, p<.01)$ with a medium effect size $\left(f^{2}=0.155\right)$ and a small predictive relevance $\left(Q^{2}=0.089\right)$. It is also found that PMSB showed a significant positive relationship on FIT $(\beta=0.440, p<.01)$ with a medium effect size ( $f^{2}$ $=0.248$ ) supporting the $\mathrm{H}_{4}$ hypothesis. Furthermore, there was a significant positive relationship between PMSB and OC $(\beta=0.371, p<.01)$ with a medium effect size ( $f^{2}=$ 0.188 ) thus supporting the $\mathrm{H}_{8}$ hypothesis.

he $\mathrm{H}_{2}$ hypothesis is supported as there is a significant positive relationship between mission clarity and sense of mission $(\beta=0.488, p<.01)$ with a fairly large effect size ( $f^{2}$ $=0.313)$. Furthermore, VC had a significant positive effect on FIT $(\beta=0.274, p<.01)$ thus $\mathrm{H}_{5}$ hypothesis is supported. This had a small effect size $\left(f^{2}=0.084\right)$. However, VC was not significantly related to $\mathrm{OC}$. Thus $\mathrm{H}_{7}$ hypothesis was not supported.

Finally, PMSB $(\beta=0.440, p<.01)$, VC $(\beta=0.274, p<.01)$ and $M C(\beta=0.171$, $p<.05)$ showed significant positive relationship with FIT. The FIT construct, in turn, showed a significant positive effect $(\beta=0.479, p<.01)$ on organisation outcomes, supporting $\mathrm{H}_{6}$. The contribution of FIT on $\mathrm{OC}$ is more instrumental when compared to PMSB on OC ( $\beta=0.371)$ whereas VC is not related to OC. Further analysis was conducted to analyse the relationship of VC on OC. Although FIT was not initially construed as a mediator, FIT was tested as a mediator to investigate further the relationship. Since PMSB is co-aligned with VC, both are tested as well. The method used is based on Preacher and Hayes (2004) as describe by Hair et al. (2014) which involves bootstrapping the indirect effect. When FIT was removed from the model, the direct effects were found to be significant, VC on OC $(\beta=0.220, p<.05)$ and PMSB on OC $(\beta=0.586, p<.01)$. However, when FIT was included as mediator in the model and the indirect effects were assessed by bootstrapping with 5,000 subsamples, the indirect effect of VC on OC via FIT was significant $(\beta=0.131, p<.01, \mathrm{VAF}=0.275)$ and PMSB on OC via FIT was significant $(\beta=0.211, p<.01$, VAF $=0.637)$. According to Hair et al. (2014), VAF values of between 0.2 and 0.8 (inclusive) indicates partial mediation. Therefore, this situation is characterised as partial mediation; $27.5 \%$ of VC's effect on OC and $63.7 \%$ of PMSB's effect on OC is explained by the FIT mediator. Because the effect size of $\mathrm{VC}$ on OC is very small $\left(f^{2}=0.004\right)$, the $27.5 \%$ mediation by FIT renders the direct effect insignificant when the model was considered as a whole. A bigger sample size is needed to detect the direct effect of VC on OC.

\section{Importance Performance Matrix Analysis}

A posthoc importance-performance matrix (IPMA) was done using organisation outcomes as the target construct (See Table 5). IPMA is useful in extending the 
findings of PLS-SEM results (Hair Jr et al., 2014) because the matrix can determine the relative importance and performance of the endogenous constructs. The interpretation of the IPMA matrix (see Figure 2) is based on Martilla and James (1977), Evans and Chon (1989), Hemmasi, Strong and Taylor (2011) and Chu and Choi (2000). FIT and MC fell in Quadrant II of high importance and high performance (top right). These constructs were perceived by respondents as very important and at the same time the organisations seemed to have high performance on these. This position in the graph indicates that there should be continued research to study these constructs; "to keep up the good work" as indicated by Chu and Choi (2000). VC and PMSB constructs fell in Quadrant IV of high performance but low importance (top left). This means respondents felt satisfied with the performance of the construct, but they felt that too many efforts were spent focusing on the construct. The message here indicated that there may be a "possible overkill" (Chu \& Choi, 2000).

Table 5: Index Values and Total Effects

\begin{tabular}{lll}
\hline & $\begin{array}{l}\text { Total effect of the latent variable Organisation } \\
\text { Outcomes (Importance) }\end{array}$ & Index Values (Performances) \\
\hline MC & 0.554 & 65.780 \\
PMSB & 0.301 & 55.000 \\
SOM & 0.111 & 89.167 \\
FIT & 0.667 & 81.154
\end{tabular}

Note. MC = Mission Clarity, PMSB = Performance management system bundle, FIT = PMSB-SOM Fit, OC = Organisation outcomes

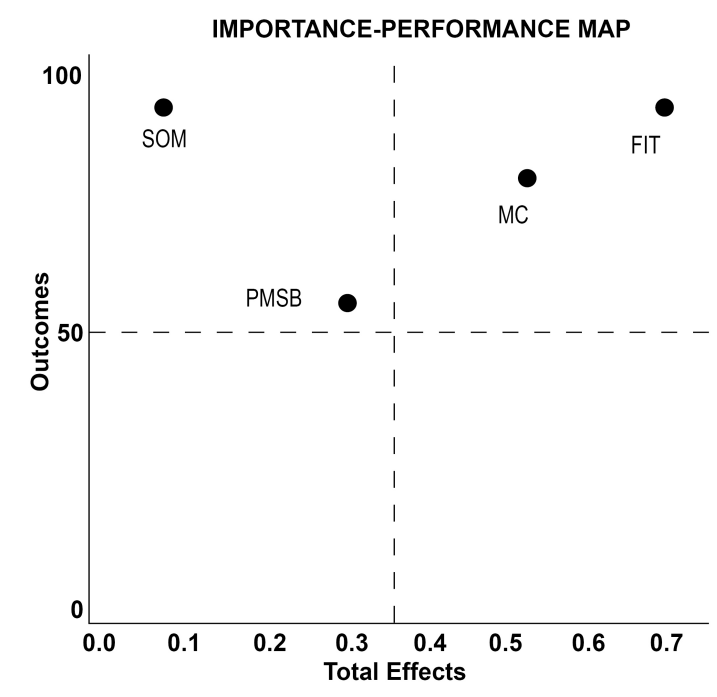

Figure 2 


\section{Discussion}

The results of this study reveal a few important insights. The PMSB construct represents organisation strategic alignment to the mission statement. There are no surprises here as the results support past studies which indicated the importance of mission statement clarity for organisational strategic alignment (Bart et al., 1998; Bart, 1997; Desmidt et al., 2011; Sattari et al., 2011; Stone, 1996) and strategic alignment is positively linked to organisation outcomes (Braun et al., 2012; Koon, 2015). Furthermore, the results indicate that strategic alignment contributes positively towards a fit situation which is in line with Guest (1994) who suggested that human resource practices like recruitment, orientation and training can contribute towards sustaining shared norms and values. The results also support the study by Hartog and Verburg (2004) who suggested that strategic alignment can contribute towards a fit situation.

The VC construct represents the organisational cultural alignment to the mission statement. Past studies have shown that the mission statement can reflect and ameliorate the values of the organisation (Bart, 1997; Bartkus \& Glassman, 2008; Ireland \& Hitt, 1992; Paulins, Hillery, \& Sturgill, 2016). However, very little is known whether increased mission clarity is linked to stronger culture. Our study shows that greater degree of clarity in the content of the mission statement in articulating the desirable values and ethical standards will help strengthen the culture.

A strong culture provides a motivational impetus to inspire the employees (David, 1989) and makes them identify with the organisation's purposes and goals (Campbell \& Yeung, 1991). Hence, it is important to articulate clearly the norms, values and ethical standards to employees as the benefits of a higher sense of mission involves a strong emotional engagement employees have with the organisation (Campbell et al., 1992). Furthermore, a stronger culture improves the perception of fit. This is in line with the findings of past studies (Carroll et al., 2011; Chow \& Shan, 2007; Pascale \& Athos, 1982) indicating that the organisation culture can improve employee attitude and perception towards organisation structure.

By comparing the beta values, the results confirm that achieving a reinforcing fit is more important than strategic alignment alone in contributing towards organisational performance. This indicates that in a situation where strategic alignment exists without a complimenting cultural alignment for a fit situation to arise, the performance of the organisation will be less than ideal. Past studies within the strategic school that revealed mixed and conflicting results (Bart \& Baetz, 1998; Desmidt et al., 2011). Our study provides a possible explanation for these cases in that they may be suffering from cultural misalignment. Therefore, this study demonstrates how the mission statement can be rendered an effective management tool by integrating strategic and cultural alignment to achieve such a fit situation.

\section{Future research directions}

Survey have shown that large companies use management tools more than small companies (Rigby \& Bilodeau, 2013). In this study, respondents were not differentiated according to the size of the companies. It can be argued that large 
companies be more demanding and complex and therefore more suitable to test the full efficacy of the mission model, especially in large service orientated organisation where human resource issues are more pronounced. Future studies thus should examine the fit model in the context of larger corporations like publicly listed companies.

In this study, the perceptions of managers were surveyed regarding the mission statement in their companies. A recent research claims that past studies on the mission statement centred on the management perspective and assume "that employees simply receive and enact" this perspective (Kopaneva \& Sias, 2015, p. 375). They claimed that there is a lack of congruence between employees' version of the mission statement and the management's version and have indicated a need to study further how the concept of mission clarity shapes shared understanding. Therefore, another important area for future studies is to determine whether differences between management's and employees' version mission has any impact of mission statement effectiveness and what are their relationships with shared goals.

Finally, future studies should revisit the value congruence construct and test the mission model with a bigger sample size as this study has found its effect size on organisational outcomes as very small. Furthermore, the fit construct deserves further investigations. Organisational studies adopt multiple perspectives (Bolman \& Deal, $1991,2008)$ for a more robust analysis. The fit construct can be studied in term of political alignment as well besides the strategic and cultural aspects. Furthermore, apart from PMSB and VC used in this study, other strategic and cultural instruments should be utilised in model testing.

\section{Limitations}

This study used a cross-sectional design to survey respondents' perception at one point in time. It does not allow us to ascertain the change in perception of respondents over time. For instance, acceptance of a new policy that does not 'fit' well with the values of the company may change over time.

Self-evaluation in a cross-sectional research design is prone to suffer from common method bias which is the variance due to measurement method which can skew observations and lead to Type I and Type II errors. Although this is shown not to be of significant effect future studies should consider using multiple respondents in their survey.

This study surveyed managers to assess their perception regarding the mission statement in the companies they are attached to. The views of CEOs and employees were not taken into account which may offer further insights into the model.

This study did not focus on generalisability of results to the population but instead focused on testing a new hypothetico-deductive model using quantitative methods of falsifying hypotheses. Therefore, the results cannot be easily generalised from the sample to the population but instead meant to confirm the new model. 


\section{Conclusion}

A new approach which involves an extension of Campbell's (1991) mission model in studying mission statement effective is posited by using a fit perspective in integrating ideas from the two schools of thought. Mission clarity is a necessary condition for organisational alignment. Both the strategic alignment (performance management system bundle) and cultural alignment (value congruence) contribute positively towards the fit construct. However, the fit construct has a stronger positive impact on organisation outcomes than strategic alignment whereas the cultural alignment has a small positive effect on organisation outcomes. The posthoc analysis using IPMA reveals that organisations should continue to focus on the fit and mission clarity constructs because they are regarded high in importance and performance. The fit perspective provides an effective integration point for the two schools of thought offering a new approach in mission statement studies as a significant contribution towards unravelling the 'black box' (Desmidt \& Heene, 2003; Desmidt et al., 2011; Desmidt \& Prinzie, 2009) between a mission statement and organisational performance.

\section{References}

Alavi, M., \& Karami, A. (2009). Managers of small and medium enterprises: Mission statement and enhanced organisational performance. Journal of Management Development, 28(6), 555-562. doi:10.1108/02621710910959729

Alvesson, M. (2012). Understanding organizational culture. Sage.

Analoui, F., \& Karami, A. (2002). CEOs and development of the meaningful mission statement. Corporate Governance: The International Journal of Business in Society, 2(3), 13-20.

Anderson, J. C., \& Gerbing, D. W. (1988). Strategic equation modeling in practice: a review and recommended two-step approach. Psychological Bulletin, 103(3), 411.

Atrill, P., Omran, M., \& Pointon, J. (2005). Company mission statements and financial performance. Corporate Ownership and Control, 2(3), 28-35.

Babnik, K., Breznik, K., Dermol, V., \& Trunk Širca, N. (2014). The mission statement: Organisational culture perspective. Industrial Management \& Data Systems, 114(4), 612-627.

Bagozzi, R. P., Yi, Y., \& Phillips, L. W. (1991). Assessing construct validity in organizational research. Administrative Science Quarterly, 421-458.

Barclay, D., Higgins, C., \& Thompson, R. (1995). The partial least squares (PLS) approach to causal modeling: Personal computer adoption and use as an illustration. Technology Studies, 2(2), 285-309.

Bart, C. (1997). Sex, lies, and mission statements. Business Horizons. Retrieved from http://www.sciencedirect.com/science/article/pii/S0007681397900628/pdf?md5=0d30ab 9ca88a798c7e60f79fa7c3efb8\&pid=1-s2.0-S0007681397900628-main.pdf\&_valck=1

Bart, C., Archer, N. P., \& Ghasemzadeh, F. (1998). A comparison of mission statements and their rationales in innovative and non-innovative firms. International Journal of Technology Management, 16(1-3), 64-77. Retrieved from http://inderscience.metapress.com/index/JCVDXMTDXBP8NQRU.pdf 
Bart, C., \& Baetz, M. C. (1998). The relationship between mission statements and firm performance: An exploratory study. Journal of Management Studies, (November). Retrieved from http://onlinelibrary.wiley.com/doi/10.1111/1467-6486.00121/full

Bart, C., Bontis, N., \& Taggar, S. (2001). A model of the impact of mission statements on firm performance. Management Decision, 38(1), 19-35. Retrieved from http://www.emeraldinsight.com/journals.htm?articleid=865190\&show=abstract

Bart, C., \& Tabone, J. J. C. (1998). Mission statement rationales and organizational alignment in the not-for-profit health care sector. Health Care Management Review, 23(4), 54-69. Retrieved from http://journals.Iww.com/hcmrjournal/Abstract/1998/10000/Mission_Statement_Rationale s_and_Organizational.5.aspx

Bartkus, B., \& Glassman, M. (2008). Do firms practice what they preach? The relationship between mission statements and stakeholder management. Journal of Business Ethics, 83(2), 207-216. doi:10.1007/s10551-007-9612-0

Bennis, W. (1991). The 4 competencies of leadership. In D. Kolb, I. Rubin, \& J. Osland (Eds.), Organizational Behavior Reader (p. 689). New Jersey: Prentice-Hall International Inc.

Bennis, W., \& Nanus, B. (1985). Leaders: The strategies for taking charge. Harper \& Row.

Bolman, L., \& Deal, T. (1991). Leadership and management effectiveness: a multi-frame, multi-sector analysis. Human Resource Management, 30(4), 509-534.

Bolman, L., \& Deal, T. E. (2008). Reframing organizations: Artistry, choice and leadership (Wiley Desktop Editions) Author: Lee G. Bolman, Terrence E. Deal. Jossey-Bass.

Braun, S., Wesche, J., Frey, D., \& Weisweiler, S. (2012). Effectiveness of mission statements in organizations: A review. Journal of Management \& Organization, 18(4), 430-444. Retrieved from http://ojs.e-contentmanagement.com/index.php/jmo/article/view/1761

Cable, D. M., \& DeRue, D. S. (2002). The convergent and discriminant validity of subjective fit perceptions. Journal of Applied Psychology, 87(5), 875-884. doi:10.1037//00219010.87.5.875

Cady, S., \& Wheeler, J. (2011). Mission, vision, and values: What do they say? Organization Development Journal, 29(1), 63-78. Retrieved from http://search.ebscohost.com/login.aspx?direct=true\&profile=ehost\&scope=site\&authtyp $\mathrm{e}=\mathrm{crawler} \& \mathrm{jrnl}=08896402 \& \mathrm{AN}=64362497 \& \mathrm{~h}=\mathrm{tQ}$ 5Voww8gulmOKiO$/ \mathrm{L} 8 \mathrm{C} / \mathrm{tg} 094 x \mathrm{~K} 1 \mathrm{iS9Ti}$ qDy0f4B3iiwsNO2xqqr+TXx+4Cp+YD/2pDDW+vdyPBjxDbf0Js3Q==\&crl=c

Campbell, A., Nash, L. L., Devine, M., \& Young, D. (1992). A sense of mission: Defining direction for the large corporation, 1993.

Campbell, A., \& Yeung, S. (1991). Creating a sense of mission. Long Range Planning, 24(4), 1020.

Carroll, W., Dye, K., \& Wagar, T. (2011). Role of organizational culture in strategic human resource management. In N. M. Ashkanasy, C. P. M. Wilderom, \& M. F. Peterson (Eds.), The Handbook of Organizational Culture and Climate (p. 664). Sage Publications.

Chin, W. W. (1998). The partial least squares approach to strategic equation modeling. Modern Methods for Business Research, 295(2), 295-336.

Chow, I. H.-S., \& Shan, S. L. (2007). Business strategy, organizational culture, and performance outcomes in China's technology industry. People and Strategy, 30(2), 47.

Chu, R. K. S., \& Choi, T. (2000). An importance-performance analysis of hotel selection factors in the Hong Kong hotel industry: A comparison of business and leisure travellers. Tourism Management, 21(4), 363-377.

Cohen, J. (1988). Statistical power for the social sciences. Hillsdale, NJ: Laurence Erlbaum and Associates. 
Cohen, J., Cohen, P., West, S. G., \& Aiken, L. S. (2013). Applied multiple regression/correlation analysis for the behavioral sciences. Routledge.

Collins, J. C., \& Porras, J. (2002). Built to last: Successful habits of visionary companies. Harper Collins.

David, F. (1989). How companies define their mission. Long Range Planning, 22(1), 90-97.

David, M., David, F. R., \& David, F. (2014). Mission statement theory and practice: a content analysis and new direction. International Journal of Business, Marketing, \& Decision Science, $\quad 7(1), \quad 95-110$. $\quad$ Retrieved from http://search.ebscohost.com/login.aspx?direct=true\&db=bth\&AN=97940355\&site=edslive

DeNisi, A., \& Smith, C. E. (2014). Performance appraisal, performance management, and firmlevel performance: A review, a proposed model, and new directions for future research. The Academy of Management Annals, 8(1), 127-179.

Desmidt, S., \& Heene, A. (2003). Mission statements: In search for ameliorated performance through organisation-employee value congruence. In The First workshop of the EGPA Study Group on Ethics and Integrity of Governance,< https://www. law. kuleuven. be/linc/integriteit/EGPA/previous\% 20egpa\% 20conferences/lisbon (Vol. 202003).

Desmidt, S., \& Prinzie, A. (2009). Does your mission statement have any value? An explorative analysis of the effectiveness of mission statements from a communication perspective. Ghent University, Faculty of Economics and Business Administration.

Desmidt, S., Prinzie, A., \& Decramer, A. (2011). Looking for the value of mission statements: A meta-analysis of 20 years of research. Management Decision, 49(3), 468-483. doi:10.1108/00251741111120806

Drazin, R., \& Van de Ven, A. (1984). An examination of alternative forms of fit in contingency theory. DTIC Document.

Drucker, P. F. (1954). The practice of management. Harper Business.

Drucker, P. F. (1974). Management: Tasks, responsibilities, practices. Management tasks Responsibilities Practices. Harper Business. Retrieved from http://books.google.com/books?id=9a5SAlaY-X4C\&pgis=1

Evans, M. R., \& Chon, K.-S. (1989). Formulating and evaluating tourism policy using importanceperformance analysis. Journal of Hospitality \& Tourism Research, 13(3), 203-213.

Faul, F., Erdfelder, E., Lang, A.-G., \& Buchner, A. (2007). G* Power 3: A flexible statistical power analysis program for the social, behavioral, and biomedical sciences. Behavior Research Methods, 39(2), 175-191.

Ford, R., Sivo, S., Fottler, M., Dickson, D., Bradley, K., \& Johnson, L. (2006). Aligning internal organizational factors with a service excellence mission: An exploratory investigation in health care. Health Care Management Review, 31(4), 259-269.

Fornell, C., \& Larcker, D. F. (1981). Evaluating strategic equation models with unobservable variables and measurement error. Journal of Marketing Research, 39-50.

Gholami, R., Sulaiman, A. B., Ramayah, T., \& Molla, A. (2013). Senior managers' perception on green information systems (IS) adoption and environmental performance: Results from a field survey. Information \& Management, 50(7), 431-438.

Gold, A. H., \& Arvind Malhotra, A. H. S. (2001). Knowledge management: An organizational capabilities perspective. Journal of Management Information Systems, 18(1), 185-214.

Guest, D. E. (1994). Organizational psychology and human resource management: Towards a European approach. European Journal of Work and Organizational Psychology, 4(3), 251-270.

Haas, J. W., Sypher, B. D., \& Sypher, H. E. (1992). Do shared goals really make a difference? 
Management Communication Quarterly, 6(2), 166-179.

Hair Jr, J. F., Hult, G. T. M., Ringle, C., \& Sarstedt, M. (2014). A primer on partial least squares strategic equation modeling (PLS-SEM). Sage Publications.

Hartog, D. N., \& Verburg, R. M. (2004). High performance work systems, organisational culture and firm effectiveness. Human Resource Management Journal, 14(1), 55-78.

Hemmasi, M., Strong, K. C., \& Taylor, S. A. (2011). Measuring service quality for strategic planning and analysis in service firms. Journal of Applied Business Research (JABR), 10(4), 24-34.

Henseler, J., Ringle, C. M., \& Sarstedt, M. (2015). A new criterion for assessing discriminant validity in variance-based strategic equation modeling. Journal of the Academy of Marketing Science, 43(1), 115-135. doi:10.1007/s11747-014-0403-8

Henseler, J., Ringle, C. M., \& Sinkovics, R. R. (2009). The use of partial least squares path modeling in international marketing. Advances in International Marketing (AIM), 20, 277-320.

Hirota, S., Kubo, K., Miyajima, H., Hong, P., \& Park, Y. W. (2010). Corporate mission, corporate policies and business outcomes: Evidence from Japan. Management Decision, 48(7), 1134-1153. doi:10.1108/00251741011068815

Holladay, S. J., \& Coombs, W. T. (1993). Communicating visions an exploration of the role of delivery in the creation of leader charisma. Management Communication Quarterly, $6(4), 405-427$.

Holladay, S. J., \& Coombs, W. T. (1994). Speaking of visions and visions being spoken an exploration of the effects of content and delivery on perceptions of leader charisma. Management Communication Quarterly, 8(2), 165-189.

Ireland, R., \& Hitt, M. (1992). Mission statements: Importance, challenge, and recommendations for development. Business Horizons, 35(3), 34-42. Retrieved from http://scholar.google.com/scholar?hl=en\&btnG=Search\&q=intitle:mission+statements $+\mathrm{i}$ mportance,+challenge,+and+recommendations+for+development\#0

Jiang, K., Lepak, D., Hu, J., \& Baer, J. (2012). How does human resource management influence organisational outcomes? Academy of Management Journal, 55(6), 12641294.

Khatri, N., Wells, J., McKune, J., \& Brewer, M. (2006). Strategic human resource management issues in hospitals: A study of a university and a community hospital. Hosp Top, 84(4), 9-20.

Klemm, M., Sanderson, S., \& Luffman, G. (1991). Mission statements: Selling corporate values to employees. Long Range Planning, 24(3), 73-78. doi:10.1016/0024-6301(91)90187-S

Koon, V.-Y. (2014). Examining HRM practices as mediator. Journal of Strategic Human Resource Management, 3(1).

Koon, V.-Y. (2015). The impact of strategic human resource management on employee outcomes in private and public limited companies in Malaysia. Journal of Human Values, 21(2), 75-86.

Kopaneva, I., \& Sias, P. M. (2015). Lost in translation: Employee and organizational constructions of mission and vision. Management Communication Quarterly, 29(3), 358-384.

Ledoux, M. W. (2005). Institutional mission and identity: How do we carry the culture to the electronic forum? Educational Technology \& Society, 8(4), 191-197.

Levitt, T. (1960). Marketing myopia. Harvard Business Review, 38(4), 24-47.

Liang, H., Saraf, N., Hu, Q., \& Xue, Y. (2007). Assimilation of enterprise systems: The effect of institutional pressures and the mediating role of top management. MIS Quarterly, 59- 
87.

Martilla, J. A., \& James, J. C. (1977). Importance-performance analysis. The Journal of Marketing, 77-79.

Martin, R. L. (2014). The big lie of strategic planning. Harvard Business Review, Jan-Feb, 79-84. Retrieved from http://hbr.org/2014/01/the-big-lie-of-strategic-planning/ar/1

Mullane, J. V. (2002). The mission statement is a strategic tool: When used properly. Management Decision, 40(5), 448-455. doi:10.1108/00251740210430461

O'Reilly, C. A., \& Chatman, J. (1986). Organizational commitment and psychological attachment: The effects of compliance, identification, and internalization on prosocial behavior. Journal of Applied Psychology, 71(3), 492.

Pascale, R., \& Athos, A. (1982). Art of Japanese management. Penguin Books.

Paulins, V. A., Hillery, J. L., \& Sturgill, A. (2016). Ethical business leadership: A simulation to develop value-driven mission statements. Developments in Business Simulation and Experiential Learning, 43(1).

Pearce, J. A., \& David, F. (1987). Corporate mission statements: The bottom line. The Academy of Management Executive, 1(2), 109-115. Retrieved from http://amp.aom.org/content/1/2/109.full

Podsakoff, P. M., MacKenzie, S. B., Lee, J.-Y., \& Podsakoff, N. P. (2003). Common method biases in behavioral research: A critical review of the literature and recommended remedies. The Journal of Applied Psychology, 88(5), 879-903. doi:10.1037/00219010.88.5.879

Preacher, K. J., \& Hayes, A. (2004). SPSS and SAS procedures for estimating indirect effects in simple mediation models. Behavior Research Methods, Instruments, \& Computers: A Journal of the Psychonomic Society, Inc., 36(4), 717-731. doi:10.3758/BF03206553

Ramayah, T., Lee, J. W. C., \& In, J. B. C. (2011). Network collaboration and performance in the tourism sector. Service Business, 5(4), 411-428.

Ramayah, T., Yeap, J. A. L., \& Ignatius, J. (2013). An empirical inquiry on knowledge sharing among academicians in higher learning institutions. Minerva, 51(2), 131-154.

Rarick, C. A., \& Vitton, J. (1995). Corporate strategy: Mission statements make cents. Journal of Business Strategy, 16(1), 11-12. doi:10.1108/eb039673

Rigby, D., \& Bilodeau, B. (2013). Management tools \& trends 2013. Bain \& Company.

Ringle, C. M., Wende, S., \& Becker, J.-M. (2015). SmartPLS 3. Bönningstedt: SmartPLS. Retrieved from http://www.smartpls.com

Sattari, S., Pitt, L. F., \& Caruana, A. (2011). How readable are mission statements? An exploratory study. Corporate Communications: An International Journal, 16(4), 282292. doi:10.1108/13563281111186931

Sidhu, J. (2003). Mission statements: Is it time to shelve them? European Management Journal, 21(4), 439-446.

Siponen, M., \& Vance, A. (2010). Neutralization: New insights into the problem of employee information systems security policy violations. MIS Quarterly, 34(3), 487.

Smircich, L. (1983). Concepts of culture and organizational analysis. Administrative Science Quarterly, 28, 339-358.

Stone, R. (1996). Mission statements revisited. SAM Advanced Management. Retrieved from http://scholar.google.com/scholar?hl=en\&btnG=Search\&q=intitle:mission+statements $+r$ evisited\#0

Swales, J. M., \& Rogers, P. S. (1995). Discourse and the projection of corporate culture: The mission statement. Discourse \& Society, 6(2), 223-242. Retrieved from http://das.sagepub.com/content/6/2/223.short 
Tian, Y. (2005). Being responsible to the society: A computer-assisted text analysis of the mission statements on the Fortune 100 Companies' web sites. In annual meeting of the International Communication Association.

Venkatraman, N. (1989). Concept of fit in strategy research: Toward verbal and statistical correspondence. Academy of Management Review, 14(3), 423-444. doi:10.5465/AMR.1989.4279078

Wei, L.-Q., \& Lau, C.-M. (2005). Market orientation, HRM importance and competency: Determinants of strategic HRM in Chinese firms. The International Journal of Human Resource Management, 16(10), 1901-1918.

Wei, L.-Q., \& Lau, C.-M. (2008). The impact of market orientation and strategic HRM on firm performance: The case of Chinese enterprises. Journal of International Business Studies, 39(6), 980-995.

Williams Jr., R., Morrell, D., \& Mullane, J. (2014). Reinvigorating the mission statement through top management commitment. Management Decision, 5(3), 2-2. Retrieved from http://www.emeraldinsight.com/journals.htm?articleid=17108873\&show=abstract

Williams, L. S. (2008). The mission statement: A corporate reporting tool with a past, present, and future. Journal of Business Communication, 45(2), 94-119. Retrieved from http://ezproxy.csu.edu.au/login?url=http://search.ebscohost.com/login.aspx?direct=true \&db=bth\&AN=32476687\& site=ehost-li 